Western North American Naturalist 67(4), (C) 2007, pp. 587-592

\title{
LARGE MIXED-SPECIES DISPERSAL FLIGHTS OF PREDATORY AND SCAVENGING AQUATIC HETEROPTERA AND COLEOPTERA, NORTHERN ARIZONA, USA
}

\author{
Lawrence E. Stevens ${ }^{1}$, John T. Polhemus ${ }^{2}$, Richard S. Durfee ${ }^{3}$, and Carl A. Olson ${ }^{4}$
}

\begin{abstract}
We report 4 incidents of large (hundreds to hundreds of thousands of individuals) mixed-species flights of predatory and scavenging aquatic Heteroptera and Coleoptera. The events occurred on normal (mostly clear, calm) autumn 2005 and spring 2006 late afternoons near Flagstaff, Arizona. Flight days were either near the full moon or in advanced waning lunar periods. At least 18 species were involved in the flights, with as many as 16 species $(7$ species of Heteroptera in 3 families, 9 species of Coleoptera in 2 families) in a single flight. Heteroptera (especially from the family Corixidae) were 2-4 orders of magnitude more numerous than Coleoptera. The diasporas plummeted, with much direct mortality, onto green metal roofs, and the largest event lasted more than 2 hours. Even after 2 days, uninjured individuals failed to resume their flights. The literature suggests that such flights occur for autumn movement to winter habitats or for location of springtime habitats for reproduction. The relative proportions of species in flocks were similar neither to the relative proportions in the region nor to those in nearby livestock watering tanks, indicating that the flights consisted of nonrandom assemblages of species. These events are rare or unique observations of coordinated movement of mixed predatory and scavenging invertebrate species.
\end{abstract}

Key words: aquatic invertebrates, Arizona, Coleoptera, dispersal, mixed-species flocking, Heteroptera, predators.

Aquatic Heteroptera and Coleoptera (AHC) in arid regions must regularly disperse to new habitats to avoid desiccation, but the details of such behavior remain poorly documented. AHC disperse during daytime hours in autumn to overwintering sites, and during spring to oviposition sites (Merritt and Cummins 1996, Bilton et al. 2001), and may disperse in winter to avoid flooding (Gray and Fisher 1981). Landin (1980) reported that 2 Helophorus (Coleoptera: Helophoridae) species dispersed from a Swedish lake in spring and summer, occasionally occurring in tandem flights, but normally segregating on the basis of reproductive readiness. Desiccation of ephemeral aquatic habitats is known to stimulate Coleoptera dispersal (Zimmerman 1959). Young (1960) observed Agabus disintegratus (Crotch 1873) leaving drying ponds and flying to standing water. Kingsley (1985) observed a mass emigration of Eretes sticticus (Linnaeus 1767; Coleoptera, Dytiscidae) from a drying desert pool, but he could not determine whether they subsequently remained in a flock or dispersed individually. Velasco and Millan (1998) observed that 3 species of Sonoran Desert stream beetles started to disperse when pond water levels were reduced to a depth of $1 \mathrm{~cm}$. They also simulated the effects of drying and warming in laboratory microcosms to stimulate flight in 2 species of dytiscids, 1 hydrophilid and 1 corixid. Some flying aquatic Heteroptera taxa reportedly land on reflective surfaces, likely mistaking such surfaces for colonization sites (Schaefer and Schaefer 1979, J.T. Polhemus personal observation). Likewise, some day-flying beetles are attracted to shiny surfaces, such as metal car exteriors, plastic, and wet pavement (Larson et al. 2000).

It has generally been assumed that dispersal flights of aquatic insects primarily involve single individuals or single species, but the difficulty of tracking small, fast-flying insects has limited our understanding of dispersal behavior. Although several studies of AHC dispersal have been conducted (e.g., Ryker 1975, Nurnberger 1996, Velasco and Millan 1998, Rundle et al. 2002), we found no substantial information on AHC mixed-species flocking behavior, flock size, species composition, or flock development. Consequently, the data presented below on mass mixed-species flights provide insight into the poorly known dispersal, flight, and social

\footnotetext{
${ }^{1}$ Department of Biology, Museum of Northern Arizona, Box 1315, Flagstaff, AZ 86002. E-mail: farvana@aol.com ${ }^{2}$ Colorado Entomological Institute, 3115 South York St., Englewood, CO 80113.

3217 North 3rd Street, Suite H, Hamilton, MT 59840.

${ }^{4}$ Entomology Department, University of Arizona, Tucson, AZ 85721
} 
behavior of some AHC taxa. Such information is relevant because these insects often play important ecological roles, functioning as predators and prey in both fishless and fish-supporting bodies of water, and because the reported behavior may interfere with rooftop water harvesting. We relate the relative proportion of species in flocks to that in northern Arizona and to that in local livestock watering tanks. Specimens were identified by the junior authors and are housed at the Museum of Northern Arizona, Flagstaff.

\section{OBSERVATIONS}

The 1st instance occurred in late afternoon on 26 October 2005 at the Billingsley residence in Doney Park, east of Flagstaff, Arizona (elevation $2000 \mathrm{~m}$ ). Doney Park is a large meadow surrounded by pinyon pine (Pinus edulis Engelm.) and juniper (Juniperus spp.) woodlands. The Billingsleys have a $140-\mathrm{m}^{2}$ shallowangled Centurydrain ${ }^{\circledR}$ (Wheeling Corrugating Co. Wheeling, WV) green baked-enamel metal roof that has 2-cm-high ridges on 23-cm centers with 2 intervening 1-cm-high ridges. This ridge pattern may resemble a rippled pond surface to visually oriented flying insects that are searching for water. The Billingsleys thought they heard rain, but on inspection they found a "rain of bugs" dropping onto their roof. They estimated that hundreds to thousands of insects were involved in the flight. The insects flew in a circling swarm above the roof and began diving onto it and falling into the gutters. The Billingsleys collected a small sample for identification. The day had been seasonally normal, cool and calm, and the moon was in the advanced stages of waning. The nearest openwater habitat was approximately $3.5 \mathrm{~km}$ away. This flight involved 3 species of aquatic heteropterans, ranked in the following order: Cenocorixa utahensis (Hungerford 1925) = Hesperocorixa laevigata (Uhler 1893) >> Notonecta undulata Say 1832. As it had been a rather dry autumn up until that time, pond desiccation could not be ruled out as a stimulus for this dispersal flight.

The 2nd event also occurred at the Billingsley residence on 12 November 2005. The weather was normal, but the moon was nearly full. The event likewise occurred in late afternoon and was similar to the 1st instance, but was more strongly dominated by Hesperocorixa laevigata.
The 3rd and by far largest event occurred on 13 April 2006 at the Weiss Ranch approximately $20 \mathrm{~km} \mathrm{~N}$ of Flagstaff off Highway 89 (elevation $1950 \mathrm{~m}$ ). The ranch lies on gentle slopes dominated by pinyon pine and juniper woodland. The ranch house and barn are both roofed with Denali ${ }^{\circledR}$ (ASC Building Products, Inc.) green metal roofing, with a corrugation pattern similar to that of the Billingsleys' roof. The Weiss family also has a greenhouse roofed with reflective white plastic. The total roof area of these structures is approximately $465 \mathrm{~m}^{2}$. Like the previous events, this event occurred on a clear, calm late afternoon, on a day with a nearly full moon. The Weisses thought they heard intense rain, but on inspection they found that the noise was caused by likely hundreds of thousands of AHC striking their roofs. The event lasted for more than 2 hours, until nearly sunset, filling the gutters and the rainwater collection system. The Weisses captured at least $20 \mathrm{~L}$ of insects from their roofs and gutters. L.E. Stevens was contacted and he examined the material on 15 April and conducted a detailed analysis of a 6-L subsample. More than half of the invertebrates in these samples were dead or mortally wounded, but many remained alive and seemed little injured 2 days after the event.

The composition of the Weiss sample involved at least 16 species: 7 species of aquatic Heteroptera in 3 families (Corixidae, Notonectidae, and Saldidae) and 9 species of aquatic Coleoptera in 2 families (Dytiscidae and Hydrophilidae; Table 1). Hesperocorixa laevigata and Cenocorixa spp. (Corixidae) were each represented by several tens of thousands of individuals in the overall 20-L sample. Hygrotus wardii (Clark 1862), the most common aquatic beetle, was at least 2 orders of magnitude less common than the corixids, and the 3 least abundant species were represented by single individuals.

We tested whether a species' relative frequency in the Weiss sample was commensurate with its regional frequency. We ranked each species' dominance in the Weiss sample with that species' ranked relative distributional frequency (RDF) in the region, using data from Stevens and Polhemus (in press) and Stevens and Durfee (unpublished data; Table 1). RDF was calculated as the proportion of southern Colorado Plateau localities at which a species was detected in relation to all sites sampled 


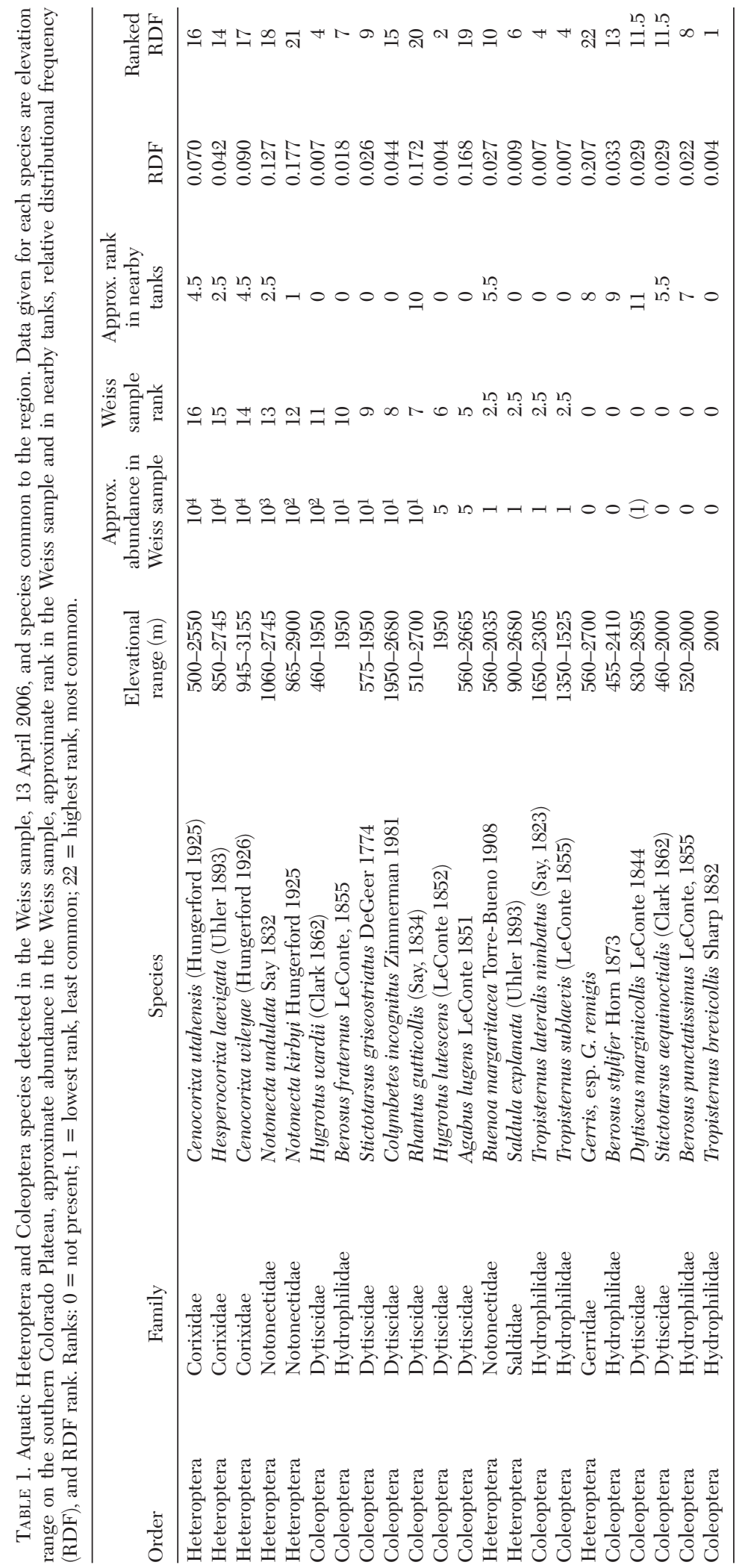


for those taxa. RDF was calculated separately for aquatic Heteroptera and aquatic Coleoptera; those values were then pooled and ranked. RDF may be biased by sampling intensity and ease of capture, but it provides a general estimate of a species' rarity in the region, information that otherwise is unavailable. Spearman analysis showed that ranked regional RDF was not correlated with ranked dominance in the Weiss sample $\left(R_{\text {Spearman, 21 }}=0.290, P=\right.$ 0.191; Table 1).

The 4th event took place at the Billingsley house on 20 April 2006. As with the other events, this event occurred on a clear, relatively calm late afternoon with a seasonally appropriate temperature on a day with a waning quarter moon. The Billingsleys documented this event more carefully, and they found that it involved approximately 800 aquatic Heteroptera (primarily H. laevigata and Cenocorixa spp.), which descended upon their roof over the course of an hour, from about 17:00 to 18:00. A single specimen of the hydrophilid beetle Tropisternus brevicollis Sharp 1882 also was recovered from this event. No previous or subsequent AHC dispersal events have occurred at either the Weiss or the Billingsley residences as of June 2007.

Subsequent to the 13 April 2006 event, the Weisses collected single individuals of Dytiscus marginicollis LeConte 1844 (Coleoptera: Dytiscidae) and Hydrophilus triangularis Say 1823 (Coleoptera: Hydrophilidae) in their gutter system in June 2006. These observations suggest that other regionally common aquatic Coleoptera may be similarly attracted to green metal roofing, but may disperse singly, rather than in flocks.

AHC commonly co-occur in stock tanks in this region and persist under ice during winter. We have detected most of the species involved in the mass flights during inventories of the region's aquatic habitats (Stevens and Polhemus in press, L.S. Stevens and R.S. Durfee unpublished data; University of Arizona Entomology Department collections-C.A. Olson); however, the relative dominance of AHC taxa in nearby bodies of water differs from that of the flocking events described above. Five nearby stock tanks examined by L.E. Stevens in spring 2006 supported more aquatic Heteroptera than Coleoptera and collectively revealed dominance by Notonectidae and Corixidae, with several Coleoptera (Table 1).
Stock tanks supported some of the same beetle genera that occurred in the Weiss sample (e.g., Stictotarsus and Berosus), but different species. Although the aquatic Coleoptera fauna detected in stock tanks in 2006 was dominated by smaller Dytiscidae, the tanks we examined supported no Colymbetes incognitus, a rather large dytiscid, in either adult or larval forms, a species that was relatively common in the Weiss sample.

\section{Discussion}

While several types of socially coordinated movements of mixed predator species have been documented, our data present a rare or unique example of large, mixed-species flocking and habitat selection behavior among predatory and scavenging invertebrates (Woiwod et al. 2001). Massive single-species migrations of Orthoptera pests are well known, including acridid plague locusts in Africa (Schistocerca gregaria [Förskal 1775]; Stinner et al. 1983) and Australia (Chortoicetes terminifera [Walker 1870]; Farrow 1982), and flightless, predatory Mormon crickets (Tettigoniidae: Anabrus simplex Haldeman 1852) west, but not east, of the Rocky Mountains (Bailey et al. 2005). Movement of pairs of vertebrate predators and scavengers are typically coordinated around foraging activities. For example, ravens (Corvus corax Linnaeus 1758) appear to influence the social organization of wolves (Canis lupus Linneaus 1758; Vucetich et al. 2004), and several other such predator pairs have been reported. While large mixed-species migrations are common among raptors (e.g., Hoffman and Smith 2003), such movements do not involve much social organization. The examples of mixed-species predator movement most similar to our report are multispecies foraging flocks of passerine birds on their wintering grounds in Mexico (Hutto 1994). However, such flocks typically involve smaller numbers of bird species, and the species involved are focused more on feeding than on macrohabitat selection.

Our data indicate that visual, not olfactory or humidity, cues are used by the 18 taxa involved in mass migrations to detect potential settling habitats. As such, dispersal by these species is more likely to be diurnal. While the timing of flights in the late afternoon hours on calm, relatively clear days could be related to reduction of moisture loss during dispersal or to protection 
from diurnal flying predators (e.g., aerially foraging birds), it is more likely attributable to enhanced long-distance detection of reflective surfaces. These flights occurred on days near the full moon or in the advanced waning lunar periods, but the relevance of lunar cyclicity is uncertain. Although large AHC flock size may be advantageous for locating suitable habitat, human dwellings that resemble such habitat may prove disastrous for the diaspora. Once they had attempted colonization, the many surviving and apparently healthy AHC specimens that we examined at the Weiss Ranch did not resume flight. Green metal roofs are commonly used in northern Arizona. For example, the National Park Service and National Forest Service commonly use these same kinds of roofing material when constructing new buildings. Such roofing may have impacts on these ecologically important aquatic predatory insect populations, or on rainwater collection systems.

Ranked dominance at neither the regional level nor at local stock tanks was related to that in the Weiss sample, indicating that the dispersing assemblage was a nonrandom group of species. Although it is generally assumed that widely distributed species have greater dispersal capability, several regionally common AHC were either rare or absent in the Weiss sample. For example, no Aquarius remigis Say 1832 (the most common aquatic heteropteran in the region; $\mathrm{RDF}=0.207$ of 444 collection localities) or other Gerridae were detected in the Weiss sample or in the other events. Although Rhantus gutticollis (Say 1834) is 1 of the most widespread aquatic beetles on the southern Colorado Plateau (RDF $=0.172$ of 274 localities), it ranked 7th in dominance in the Weiss sample. Rhantus gutticollis was several orders of magnitude rarer than the 3 most common Corixidae in that sample, all of which have far lower regional RDF values. Agabus lugens LeConte 1851 is another regionally common aquatic beetle that had low dominance ranks in the Weiss sample $(\mathrm{RDF}=0.168$, Weiss rank $=5)$. Other regionally common aquatic beetles, such as Cymbiodyta dorsalis (Notschulsky 1859) $(\mathrm{RDF}=0.186)$, Tropisternus ellipticus (LeConte 1851) $(\mathrm{RDF}=0.142)$, and Stictotarsus striatellus (LeConte 1852) (RDF $=0.091)$, did not occur in the Weiss sample. We surmise that other common AHC in the region either disperse singly or may not dis- perse widely, and are less attracted to green metallic roofs or reflective white roofs.

These observations generate many new questions about AHC dispersal behavior. Are these dispersal events rare or common? How do large AHC flocks assemble-from a single source or through the merging of several individuals or smaller flocks? How far do the flocks travel? What is the impact of predator depletion on the losing pond and of predator swamping on the receiving pond? Are green and white reflective surfaces particularly attractive to these taxa (no reports of this phenomenon have been received from owners of red, blue, or silver metal roofs, which are commonly used in the region)? Why do surviving individuals not resume habitat searching? Finally, what is the relationship between this behavior and regional drought or global climate change? Answers to these and other questions will require further observation, monitoring, and innovative experimentation.

\section{ACKNOWLEDGMENTS}

This research was supported, in part, by the Museum of Northern Arizona in Flagstaff and by the Colorado Entomological Institute of Englewood. We thank the Billingsley and Weiss families for reporting information and for collecting specimens. We thank George Billingsley, Boris Kondratieff, C. Riley Nelson, and Mark C. Belk for helpful comments on the manuscript.

\section{Literature Cited}

Bailey, N.W., D.T. Gwynne, And M.G. Ritchie. 2005. Are solitary and gregarious Mormon crickets (Anabrus simplex, Orthoptera, Tettigoniidae) genetically distinct? Heredity 95:166-173.

Bilton, D.T., J.R. Freeland, and B. Okamura. 2001. Dispersal in freshwater invertebrates. Annual Review of Ecology and Systematics 32:159-181.

FARRow, R.A. 1982. Population dynamics of the Australian plague locust, Chortoicetes terminifera (Walker) in central western New South Wales: analysis of population processes. Australian Journal of Zoology 30: 569-580.

GraY, L.J., AND S.G. Fisher. 1981. Postflood recolonization pathways of macroinvertebrates in a lowland Sonoran Desert stream. American Midland Naturalist 106:249257.

Hoffman, S.W., AND J.P. Smith. 2003. Population trends in migratory raptors in western North America, 19772001. Condor 105:397-419.

Hutto, R.L. 1994. The composition and social organization of mixed-species flocks in a tropical deciduous forest in western Mexico. Condor 96:105-118. 
Kingsley, K.J. 1985. Eretes sticticus (Coleoptera: Dytiscidae) life history observations and an account of a remarkable event of synchronous emigration from a temporary desert pond. Coleopterists Bulletin 39: 7-10.

LANDIN, J. 1980. Habitats, life histories, migration and dispersal by flight of two water-beetles Helophorus brevipalpis and $H$. strigifrons (Hydrophilidae). Holarctic Ecology 3:190-201.

Larson, D.J., Y. Alarie, and R.E. Roughley. 2000. Predaceous diving beetles (Coleoptera: Dytiscidae) of the Nearctic Region, with emphasis on the fauna of Canada and Alaska. NRC Research Press, Ottawa, Ontario, Canada. 982 pp.

Merrit, R.W., And K.W. Cummins. 1996. An introduction to the aquatic insects of North America. 3rd edition. Kendall/Hunt Publishing Co., Dubuque, IA.

Nurnberger, B. 1996. Local dynamics and dispersal in a structured population of the whirligig beetle Dineutus assimilis. Oecologia 106:325-336.

Rundle, S.D., A. Foggo, V. Choisel, and D.T. Bilton. 2002. Are distribution patterns linked to dispersal mechanism? An investigation using pond invertebrate assemblages. Freshwater Biology 4:1571-1581.

RyKER, L.C. 1975. Observations on the life cycle and flight dispersal of a water beetle, Tropisternus ellipticus LeConte, in western Oregon. Pan-Pacific Entomologist 51:184-194.

Schaefer, C.W., And M.I. Schaefer. 1979. Corixids (Hemiptera-Heteroptera) attracted to automobile roof. Entomological News 90:230.
Stevens, L.E., And J.T. Polhemus. In press [accepted 20 June 2007]. Biogeography of aquatic and semiaquatic Heteroptera in the Grand Canyon ecoregion, southwestern USA. Monographs of the Western North American Naturalist 4.

Stinner, R.E., C.S. Barfield, J.L. Stimac, and L. Dohse. 1983. Dispersal and movement of insect pests. Annual Review of Entomology 28:319-335.

Velasco, J., and A. Millan. 1998. Insect dispersal in a drying desert stream: effects of temperature and water loss. Southwestern Naturalist 43:80-87.

Vucetich, J.A., R.O. Peterson, and T.A. Waite. 2004. Raven scavenging favors group foraging in wolves. Animal Behavior 67:1117-1126.

Woiwod, I.P., D.R. Reynolds, and C.D. Thomas. 2001. Insect movement: mechanisms and consequences. CABI International, Wallingford, Oxfordshire, U.K.

Young, F.N. 1960. The water beetles of a temporary pond in southern Indiana. Proceedings of the Indiana Academy of Science 69:154-164.

Zimmerman, J.R. 1959. A note on flight emigrations of water beetles from a temporary pond. Coleopterists Bulletin 13:102.

Received 2 February 2007 Accepted 13 June 2007 